руды / Тарасов П.П., Прядезников Б.Ю., Петров П.П. и др. // Хладостойкость. Новые технологии для техники и конструкций Севера и Арктики: труды Всероссийской конференции с международным участием, посвященной 70-летию профессорамеханика, д.т.н. А.В. Лыглаева. - Якутск, 2016. - С.306-310.

\title{
Анализ отказов технических средств тепловозов за 2014-2016 годы на Тындинском регионе Дальне-Восточной железной дороги
}

\author{
Руссов Д., Моисеев Н., студенты, \\ БАмИЖТ - (ф) ДВГУПС в г. Тында \\ E-mail: bamigt.makarov@mail.ru
}

Научный руководитель: стариий преподаватель Смольянинова И.А.

Анализ отказов технических средств за период 2014-2016 годы показывает «слабые» места по ремонту и обслуживанию тепловозов по Тындинскому региону. Причинами возникновения событий в пути следования чаще всего выступают отказы технических средств в части работы дизеля, вспомогательного оборудования, экипажной части, электрооборудования и электрических машин.

Для фиксирования и регистрации ОТС на сети ОАО РЖД принята автоматизированная система учета, контроля устранения отказов технических средств и анализа их надежности (КАСАНТ). После разбора, имеющиеся в 1,2,3 категориях, события или отказы относятся за организацией, допустившей в той или иной мере эти факты.

При анализе ОТС за период 2014-2016 гг. можно проследить тенденцию к увеличению или уменьшению, а также выявить наиболее часто происходящие отказы по видам оборудования тепловоза.

По результатам работы системы КАС АНТ за период 2015 года в ТЧЭ Тында поступило 1181 оповещение об отказах технических средств, против 719 случаев за аналогичный период 2014 года. В 2016 году таких случаев было 1109.

В ходе анализа допущенных отказов технических средств на основе данных системы КАС АНТ было установлено, что качество оформления и своевременность расследования производилось в строгом соответствии с распоряжением ОАО «РЖД» от 23.12.2013 № 2852p.

На основании анализа отказов технических средств по ТЧЭ-11 и для предупреждения дальнейшего увеличения ОТС были приняты следующие меры:

- выполнение приемщиками локомотивов, дежурными машинистами инструкторами проверки качества проведения цикловых работы и устранения ранее выявленных замечаний;

- ведение целенаправленной работы по выполнению в полном объёме ТО-1;

- запрет на приемку локомотивов с неустранимыми замечаниями после проведения ТО-2;

- ополнение плана технических занятий темами составленных на основе таблицы мониторинга системы КАС АНТ и анализа работы приборов безопасности. 
Распределение отказов технических средств по категориям поступивших на расследование в ТЧЭ-11

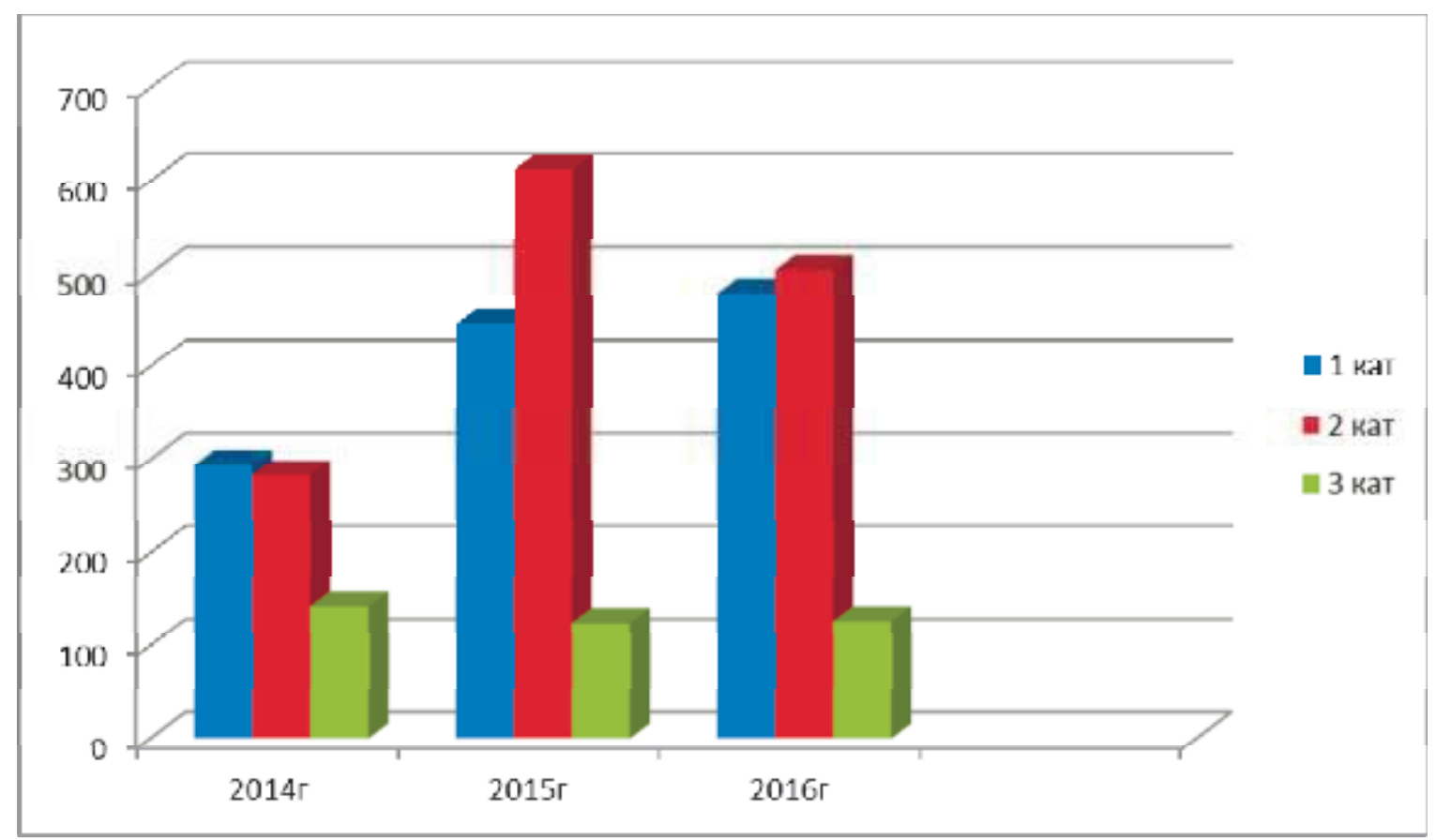

Распределение отказов по видам оборудования за 12 месяцев 2016 года (KAC AHT)

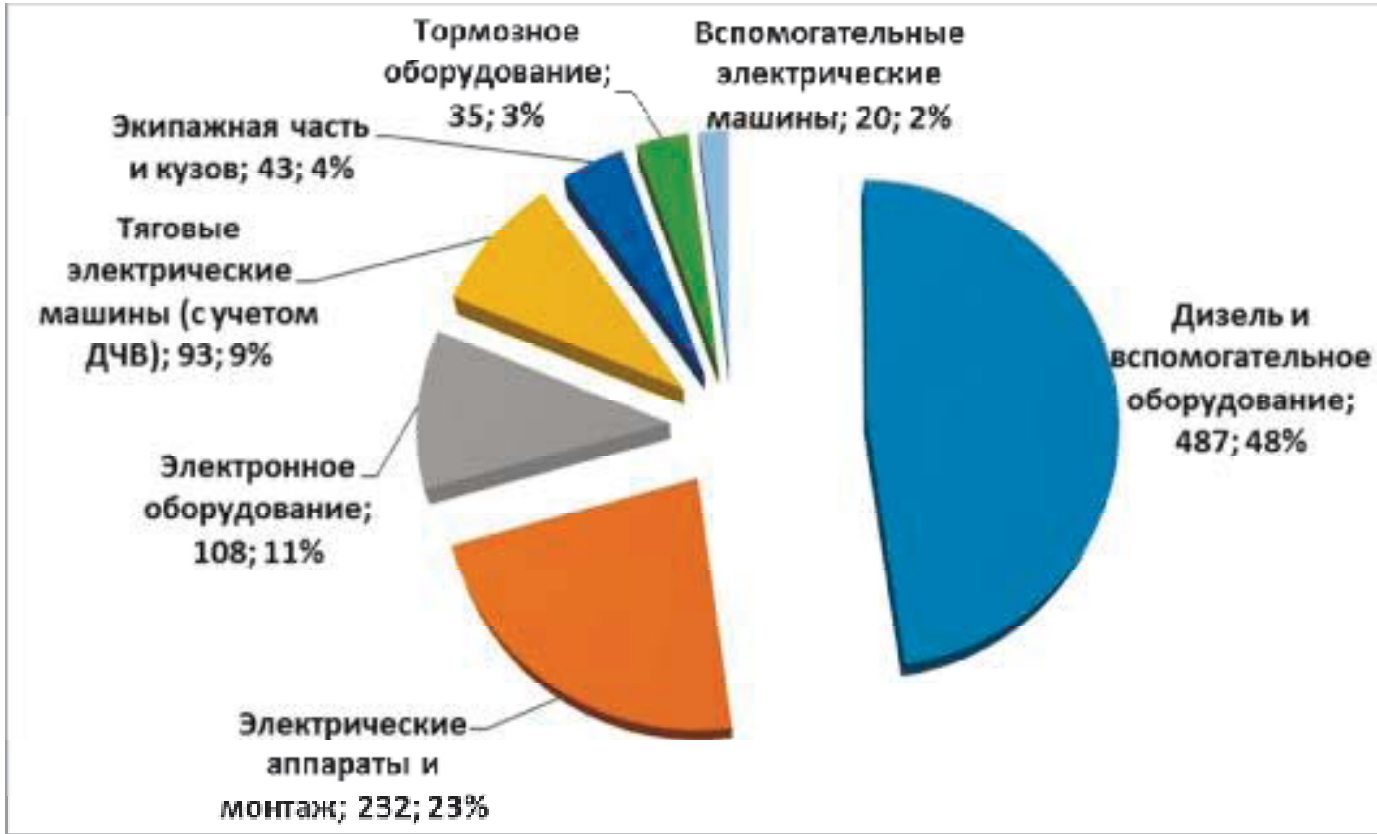




\section{Распределение отказов по видам оборудования за}

12 месяцев 2015 года (КАС АНТ)

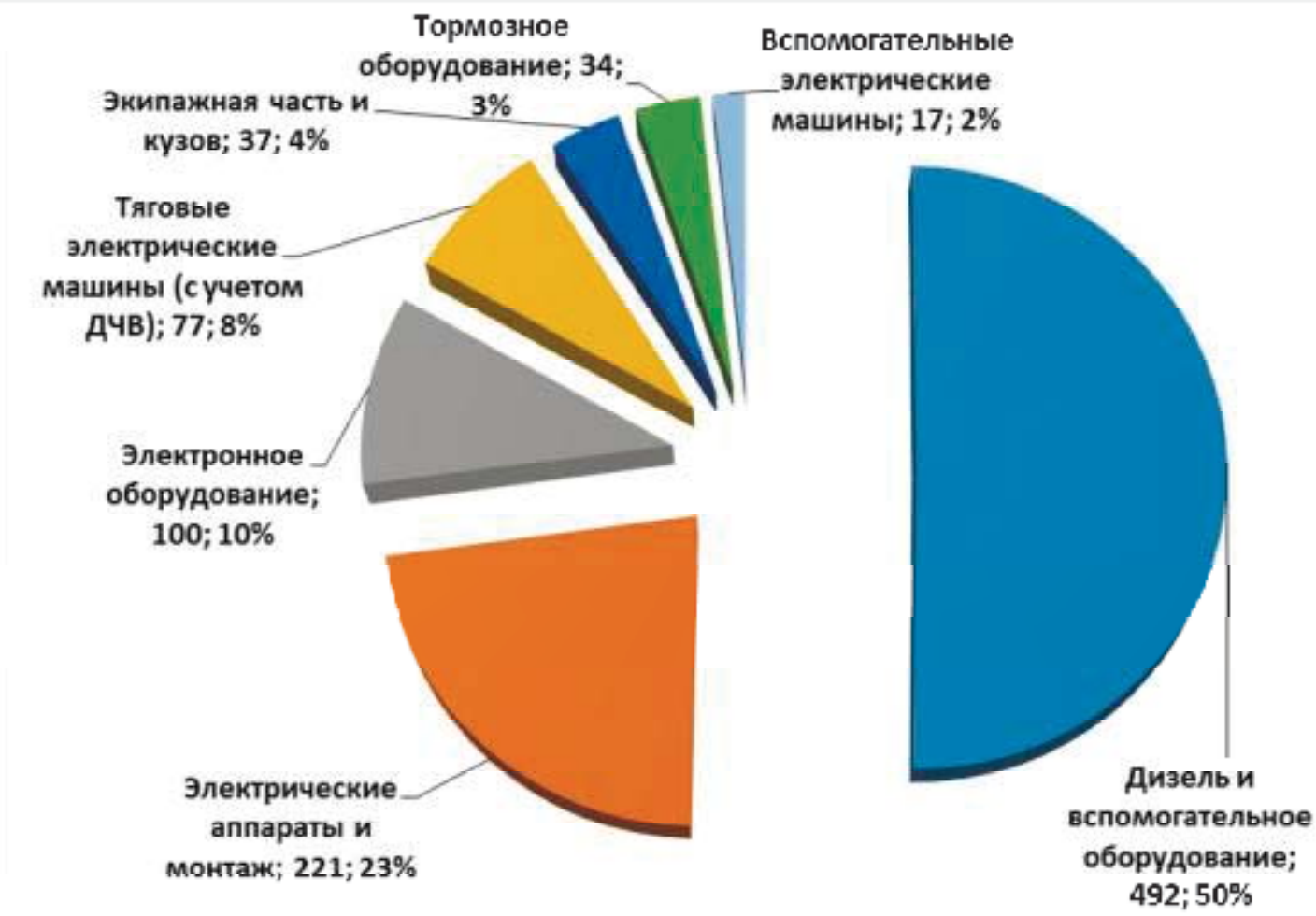

Для более наглядного ознакомления по причастным на диаграмме 5 показано распределение отказов технических средств по ответственности за организациями в системе КАС АНТ за 12 месяцев 2014-2016гг (1, 2, 3 кат.):

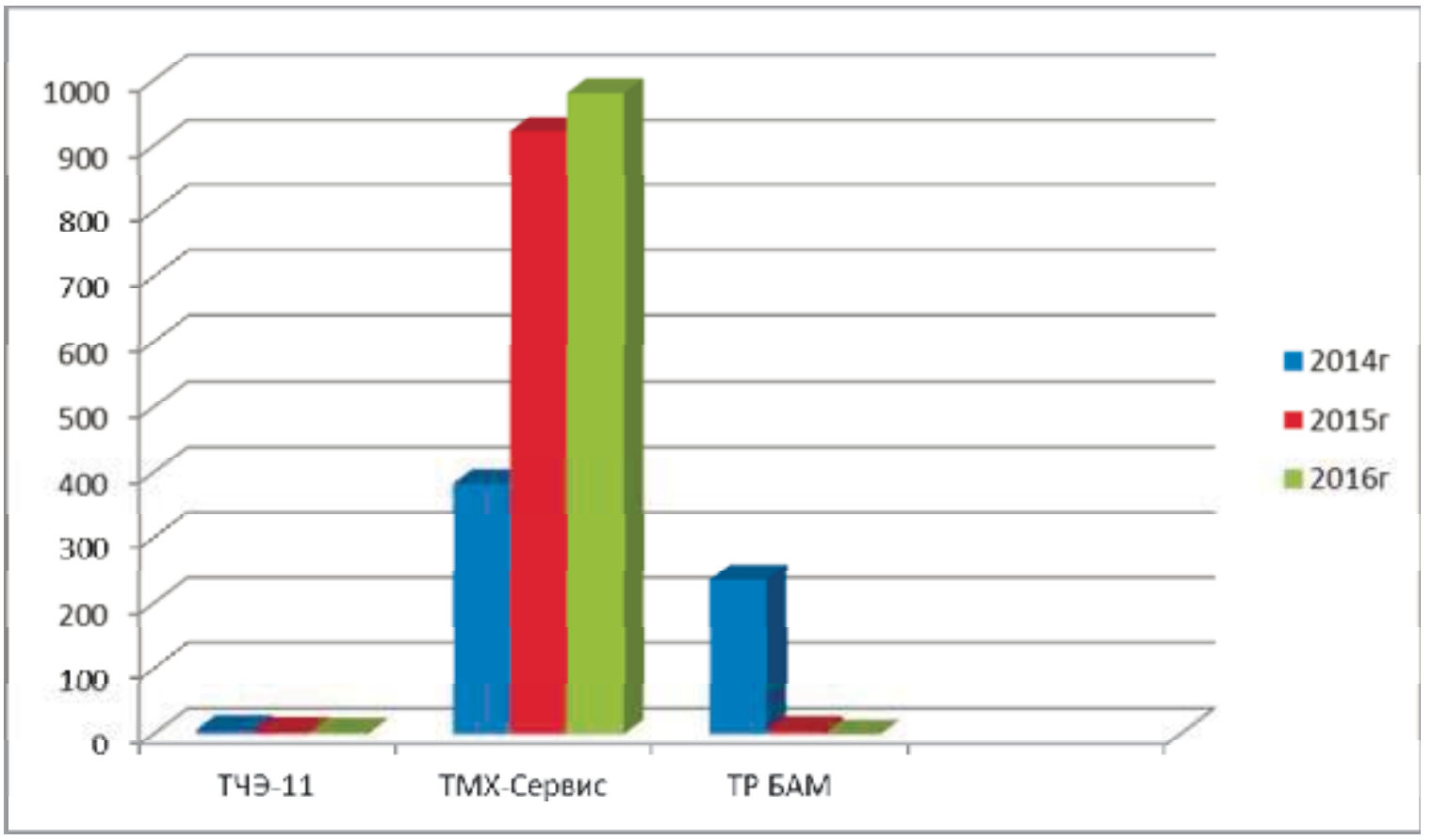

Так как в ТР БАМ ремонтируются только узлы системы локомотивной безопасности, а ТЧЭ-11 только эксплуатирует тепловозы, то, следовательно, 
наибольшее количество отказов технических средств отнесено за ТМХ- Сервис. Причинами такого количества отказов является нехватка запасных частей или их некачественное исполнение. Уменьшение количества квалифицированного персонала по ремонту подвижного состава (слесари по РПС, технологи, инженерно- технические работники), что связано с демографической ситуацией с одной стороны, уходом на пенсию или сокращение штата в связи с тяжелой экономической ситуацией (очередной экономический кризис мирового масштаба косвенно сказывается на работе Тындинского региона ОАО РЖД).

Меры, принимаемые организациями для уменьшения ОТС, учитывают показатели отказов по видам оборудования и проводят тщательное расследование каждого события с причастными.

Увеличение случаев отказа технических средств по причине не качественного ремонта, перепробегов с нарушением Распоряжения № 3р, отставление тепловозов из эксплуатируемого парка в неплановый ремонт влечет издержки материальных затрат, влияющих на качество работы локомотивного хозяйства ОАО РЖД в целом.

На Тындинском регионе ОАО РЖД проводятся испытания и обкатка новых тепловозов и увеличение веса составов на сложных участках пути, что в свою очередь требует дополнительных затрат с компенсацией их в будущем, при увеличении грузопотока с развитием зоны БАМа, как это планировалось при его строительстве.

\section{Изгибная жесткость и напряженное состояние базальтового фильтра}

Сатторов Л.Х., магистр, Эгамов Ф.А., магистр, Навоийский государственный горный институт, 2. Навои, Узбекистан E-mail: u0505@mail.ru

\section{Научный руководитель: о.m.н. Курбанов А.А.}

В настоящее время приоритетным является уделять особое внимание исследованию взаимодействия волокон с газовой и жидкой средой в процессе фильтрации, деформированного состояния материала фильтра, изгиба волокон под силового воздействия потока газа или жидкости, восстановительного процессов после снятия нагрузки давления потока. В этом плане представляет практический интерес разработка методики расчета параметров фильрующих материалов, полученных на основе местного базальтового сырья. Решение этих проблем являются весьма востребованными и позволяют создать новые технологии по организации производства базальтовые фильтры для обезвоживания золотосодержащей пульпы, с последующим использованием сточной воды в обороте водоснабжения, фильтров для очистки газов от пыли в горно-металлургической промышленности и т.д.

Анализ информации технических литературных источников и данные, полученные по линии Интернет, показывают, что при расчетах фильтрации газа и жидкостей, влияния на процесс следующих параметров таких как: эластическая и пластическая деформация, изгибная жесткость и сопротивление на изгиб базальтовых 